\title{
Maturity and shotcrete strength for early re-entry
}

\author{
P. Dight Australian Centre for Geomechanics, Australia \\ I.R. Hulls Coffey Mining Pty Ltd, Australia
}

\begin{abstract}
A significant amount of effort is being placed on achieving early re-entry for the drilling jumbos in order to reduce mining costs. In this context, shotcrete and fibrecrete have been used to stabilise the back and side walls to facilitate early re-entry. Determining the early age strength, using a soil pocket penetrometer has been shown to be inappropriate (Clements, 2004). A more reliable penetrometer, provided commercially by BASF (the Meyco ${ }^{\circledR}$ penetrometer), tends to show that the skin of the shotcrete can be relatively strong while the sub-strata is still weak. The early age strength tests performed on cylindrical examples, and Rusty Morgan beam tests, also appear to underestimate the strength of the placed shotcrete. In this paper the authors will show why the shotcrete on the back behaves (in general) much better than the routine quality assurance testing would indicate. A major determinant on the strength and curing behaviour of the shotcrete (once the shotcrete mix, additives and placement techniques have been sorted out) is the inertial temperature of the rock being excavated. This temperature has a profound influence on the early strength behaviour. It is a characteristic of mining that as underground mines get deeper the rock temperature increases. Hence the observation that rock temperature influences the behaviour of the early age shotcrete is much clearer from mining operations, than civil engineering projects where in the latter the thermal gradient is less likely to change during the course of the construction. It can also be demonstrated that the temperature of the samples being collected to undertake early strength testing are affected by the thermal inertia of the steel cylinders/formers and hence the strength is typically underestimated at ambient temperatures (approximately $22^{\circ} \mathrm{C}$ ). The strength is a function of time and temperature, also known as maturity. This is commonly used in the concrete industry where the early strength of concrete beams is needed to be understood in construction. In this paper the authors show simple techniques for measuring the temperature underground and correlating to the early strength of shotcrete.
\end{abstract}

\section{Introduction}

An aspect of safe and rapid development is the ability to optimise the use of equipment while maintaining safe working conditions. With the advent of the requirements that work should not be undertaken under unsecured ground, operators have been looking for the fastest way to secure the ground before re-entering and commencing drilling. Securing ground has been primarily undertaken by scaling, using mesh and rockbolts. In Australia, all of this work has been undertaken using drilling jumbos. There have been many applications where the shotcrete has been used to provide an alternative cover to the ground rather than mesh. The difficulty arises when trying to understand the behaviour of the freshly applied shotcrete. In this paper shotcrete has been used as a generic term to cover shotcrete and fibrecrete. This material is undergoing set and cure within the time (typically $0.5-2$ hours) that operators would like to re-enter the workings. Simple calculations, using products like Unwedge from Rocscience, have been used to show that a very weak surface support, like uncured shotcrete with a shear strength of $0.3 \mathrm{MPa}$, with a thickness of $50 \mathrm{~mm}$, is sufficient to secure a wedge of rock in the back (or roof). While there are some arguments in literature (Bernard, 2008) about the mechanism of failure of early age shotcrete this approach has been used by the mining industry. It is widely recognised that the fibre load in the shotcrete has negligible influence on the shear strength of the shotcrete prior to cracking of the shotcrete. Hence there has been most effort placed on determining the strength of the green shotcrete using relationships associated with the compressive strength. The most important question however is: "at what age (e.g. in hours) does the shotcrete achieve this shear strength?” The issues of flexural behaviour, creep or adhesion are not addressed in this paper.

There have been difficulties in measuring the early strength of shotcrete - these have typically relied on tests such as the soil pocket penetrometer, the Meyco penetrometer and the Rusty Morgan beam tests 
(Heere et al., 1999; Heere and Morgan, 2002). Samples are prepared at the same time as the shotcrete is sprayed and stored close to the operating area. At the same time quality assurance samples (steel cylinders and round determinate panels (RDP)) are prepared for testing at seven and 28 days. Another form of quality assurance is to core samples of the sprayed shotcrete for laboratory compressive strength testing. It is incidental that the samples cored from the sprayed surface often have a variance to the samples prepared according to the Australian standard and properly cured in the laboratory at $21^{\circ} \mathrm{C}$ in a fog room.

One aspect of this difference could be attributed to the fact that the shotcrete in situ is not kept moist during curing.

Another aspect is that the environment experienced, particularly in mining, appears to be having a significant effect on the early strength behaviour. The rock temperature increases at approximately $1-1.5^{\circ} \mathrm{C}$ per $30 \mathrm{~m}$ of depth below surface. The base temperature at surface is generally considered to be the average surface temperature. It is not uncommon in mines in Australia for the rock temperature near the face to be in excess of $35^{\circ} \mathrm{C}$ and has been measured up to $62^{\circ} \mathrm{C}$. At the same time, the temperature on the floor of the development, now influenced by the ventilation system, could be $5-15^{\circ} \mathrm{C}$ lower than the rock temperature. The question then arises as to whether this temperature is affecting the early strength and to what extent this may be occurring.

Arrhenus in 1889 published a paper which described the effect of temperature on the rate of a chemical reaction. Nurse (1949), and subsequently Saul (1951), as summarised in ASTM C1074-04 (2004), applied this knowledge to the set and cure time of concrete. The equation they developed is as follows:

$$
\mathrm{M}(\mathrm{t})=\Sigma\left(\mathrm{T}-\mathrm{T}_{0}\right) * \Delta \mathrm{t}
$$

Where ' $M$ ' is called the maturity, ' $T$ ' is the temperature of the concrete, ' $T_{0}$ ' is the temperature at which the cement will not react and ' $\Delta \mathrm{t}$ ' is the increment of time associated with the temperature ' $T$ ' (ASTM C107404, 2004). Maturity has been used by many people in concrete technology (Ansari et al., 1998, 1999; Ansell, 2002; Chengyu, 1989; DuFour et al., 2003; Goodrum et al., 2004; Kutcha et al., 2003; Mancio et al., 2004; Öztürk et al., 2004; Zhang et al., 2008).

This paper will present the results of work undertaken which demonstrate the influence of maturity on the early strength of shotcrete and how this applies in particular to mining projects where the environmental/inertial temperature dominates the properties.

\section{Background}

There is limited data available in the literature on early strength properties of shotcrete, in particular, less than 3.5 hours. However, it is in this timeframe that is of most interest to assist in earlier re-entry times. In addition there is scant data available on the creep/relaxation effects on the behaviour of shotcrete while still green (Georgiades, 2005). While these latter effects are of significance in squeezing ground, it is beyond this paper to examine.

The quality control/quality assurance methods adopted in mining have come from civil engineering practices. This has been well thought out and is applicable to the construction of tunnels and civil structures. A concern arises in mining when the application of seven day strength and 28 day strength tests performed, generally off-site, do not meet specification. It has been common within the mining industry to over specify the shotcrete strength because of the high variability and quality control issues. Using the Unwedge program it is apparent that the strengths required to stabilise wedges in the back are significantly less than the strengths specified.

Some of the quality control issues are:

- Poor blast control and very rough profile.

- Poor surface preparation and lack of scaling.

- Lack of correct curing (shotcrete not kept moist).

- Adhesion and progressive deterioration in acid water.

- Variable shotcrete thickness. 
Based on concrete technology the relationship between the design shear strength, $\mathrm{f}_{\mathrm{cv}}$ and the design compressive strength (AS 3600, 2001) is as follows:

$$
\mathrm{f}^{\prime}{ }_{\mathrm{cv}}=0.34 * \mathrm{f}^{\prime}{ }_{\mathrm{c}}{ }^{0.5}
$$

where ' $\mathrm{f}$ ' ' ' is the characteristic strength, which according to Bernard (2008) is approximately $90 \%$ of the mean strength in $\mathrm{MPa}$. Hence at a characteristic strength of $1 \mathrm{MPa}$, the design shear strength would be $0.34 \mathrm{MPa}$ (340 kPa) often deemed to be sufficient to hold most wedges in a $5.5 \mathrm{~m}$ wide drive. However there would be concern that the relationship still holds in the first few hours when the shotcrete is green.

\section{Table $1 \quad$ Mix 1}

\begin{tabular}{ccccccc}
\hline Aggregate & Dust & Sand & Cement & Additive & Fibre & Water \\
\hline $300 \mathrm{~kg}$ & $900 \mathrm{~kg}$ & $1700 \mathrm{~kg}$ & $450 \mathrm{~kg}$ & $18 \mathrm{~L}$ & $5 \mathrm{~kg}$ & $175 \mathrm{~kg}$ \\
\hline
\end{tabular}

There are also concerns about how the compressive strength of 1 MPa could be measured. One approach has been to use the soil pocket penetrometer. The principal of this test is to push the penetrometer into the green shotcrete and the response provides a calibrated compressive strength. This strength is a function of the area of the plunger - in the case of the soil penetrometer this is $32 \mathrm{~mm}^{2}$. Relate this to the mean expected particle size of $1 \mathrm{~mm}$; or area equal to $3.2 \mathrm{~mm}^{2}$. In the case of the Meyco penetrometer the plunger area is $3.1 \mathrm{~mm}^{2}$ and it is apparent then why the Meyco penetrometer is more reliable in determining the compressive strength of green shotcrete (Clements, 2004).

Bernard (2008) has developed an alternative preliminary shear strength equation as follows:

$$
\mathrm{f}^{\prime}{ }_{\mathrm{cv}}=0.28 * \mathrm{f}^{\prime}{ }_{\mathrm{c}}{ }^{0.6}-0.11
$$

This equation has an upper limit for the compressive strength of $100 \mathrm{MPa}$. To achieve a shear strength of $0.34 \mathrm{MPa}$, the compressive strength would be approximately $2 \mathrm{MPa}$ - this is double the strength given by Equation (2).

In terms of early re-entry, the lack of correct curing practice (i.e. not keeping the shotcrete moist) is not a significant issue. It is well known in shotcreting practice that hydration will not complete unless there is adequate moisture - and this can be applied at any stage after the shotcrete has hardened.

Again in terms of early re-entry, shotcrete fall-off is the main limiting aspect of re-entry and not specifically adhesion. One cause of the fall-off is when the thickness of the wet shotcrete is too great.

It is apparent that the deterioration in adhesion due to sulphide attack takes time (Kim et al., 2006) and is beyond the scope of this paper.

\section{Research project concept and scope}

Maturity of concrete/shotcrete is the determination of strength gained with time and temperature (ASTM C1074-04, 2004). The curing of concrete is essentially an exothermic reaction. The higher the ambient temperature the quicker the cure occurs and hence the sooner that higher strengths are attained.

The maturity concept for strength determination of concrete is regularly used within the civil construction industry and was developed in the late 1940s and early 1950s. Research over recent years has seen this approach to concrete strength estimation developed to a considerable extent. The prime focus of this research project was to determine if the maturity concept was applicable for use with shotcrete.

The initial mix design (Mix 1) is shown in Table 1. The behaviour of the mix was tested both in the laboratory and in the field where additional test procedures were also trialled. The laboratory work was planned to gain baseline data for the establishment of the maturity curve. A bulk sample of the mix was forwarded to the Coffey Mining Perth laboratory where the following tests were undertaken: 
- VICAT needle penetrometer to determine accelerator induced set times.

- 50 mm cube UCS gain with time at various temperatures.

During the initial site visit data was gathered for:

- The maturity concept where temperature gain during, and following, shotcrete application can be related to strength gain.

- The UCS strength gain of the shotcrete mix with time, using the Rusty Morgan beam test concept (Heere et al., 1999; Heere and Morgan, 2002). Sample sizes of 75 x 75 mm for testing.

- Penetrometer UCS strength tests.

- Trial beam flexural strength tests.

- Trial beam double shear tests.

The main aims of the second visit were similar to the first, but in addition to also:

- Trial the use of alternative temperature measurement techniques to speed up the gathering of temperature data as the applied shotcrete cured.

- Gather additional data for the UCS strength gain of the shotcrete mix with time, using the Rusty Morgan beam test, concentrating on 75 x 75 mm samples.

- Gather additional data for the beam double shear tests.

Table 2 Mix 2

\begin{tabular}{cccccccc}
\hline Aggregate & Dust & Sand & Cement & Silica Fume & Additive & Fibre & Water \\
\hline $300 \mathrm{~kg}$ & $1000 \mathrm{~kg}$ & $1750 \mathrm{~kg}$ & $400 \mathrm{~kg}$ & $20 \mathrm{~kg}$ & $3 \mathrm{~L}$ & $6 \mathrm{~kg}$ & $200 \mathrm{~kg}$ \\
\hline
\end{tabular}

The mix design for the second site visit was different from Mix 1. The Mix 2 design is shown in Table 2. Mix 2 differed by employing a different sand supplier, the removal of $50 \mathrm{~kg}$ of cement $/ \mathrm{m}^{3}$, additional fibres, additional dust, sand and less water. Additional laboratory work to gather baseline data for the maturity of the second mix is required.

\subsection{Site shotcrete application details}

An on-site batch plant is used to supply the mine sites. Shotcrete is applied with a Jacon 'Viper' spray unit and is transported in $5 \mathrm{~m}^{3}$ and $2 \mathrm{~m}^{3}$ agitator trucks.

The Viper unit is shown in Figure 1. 


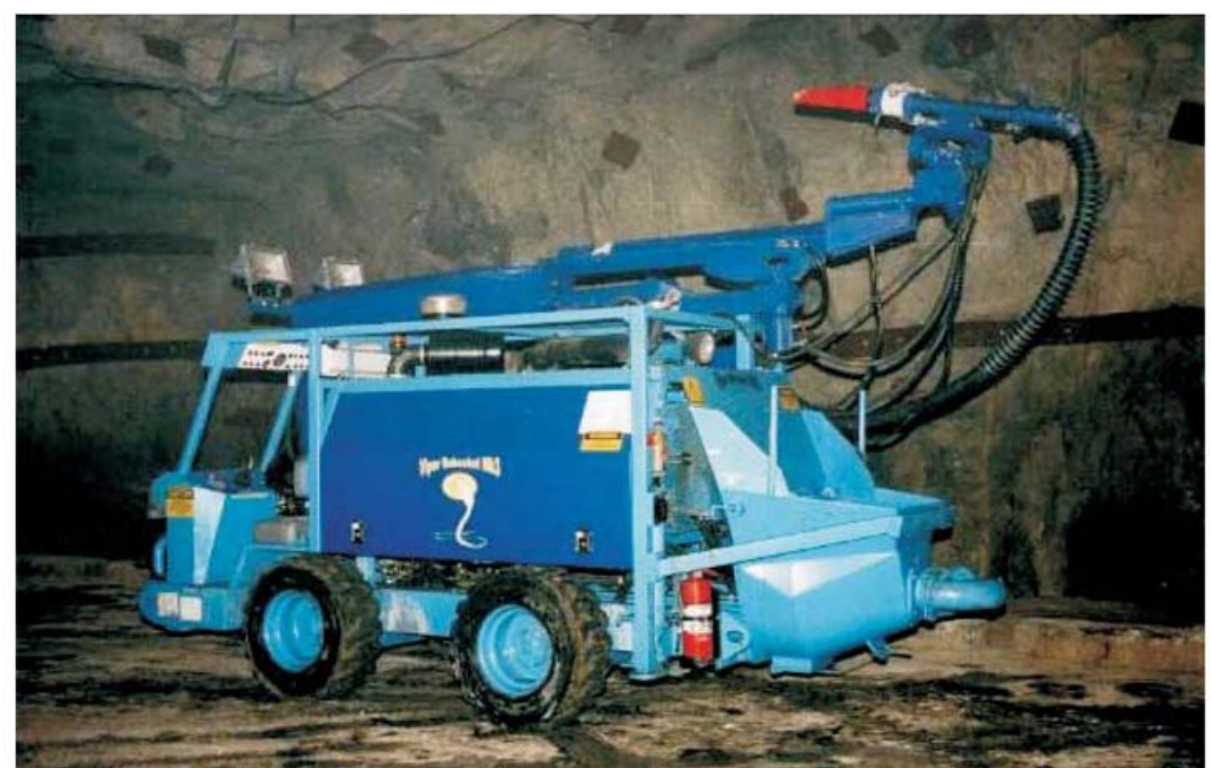

Figure 1 Viper pumping and spraying unit

\subsection{Re-entry practice}

The re-entry practice adopted at the mine was to commence bolting a particular heading after about $1-1.5$ hours post shotcrete application. At this time the applied shotcrete was generally considered green. Bolting would be suspended if the friction bolt bearing plates appear to be punching into the shotcrete. At the completion of bolting the heading was technically "supported" however it is highly probable that the ground between the installed bolts is only being given minimal support by the green shotcrete.

\subsection{Test results}

The laboratory work on Mix 1 and the two site visits where testing was undertaken on Mix 1 and Mix 2 are presented below.

\subsection{Laboratory test results}

\subsubsection{VICAT testing}

A VICAT testing apparatus was used to determine mix set times with temperature and also with various doses of accelerator. Testing was undertaken within the range of $11-40^{\circ} \mathrm{C}$. The results of the testing are shown in Figure 2 where penetration of the VICAT needle has been plotted against time. 
VICAT Laboratory Test results - July 2006

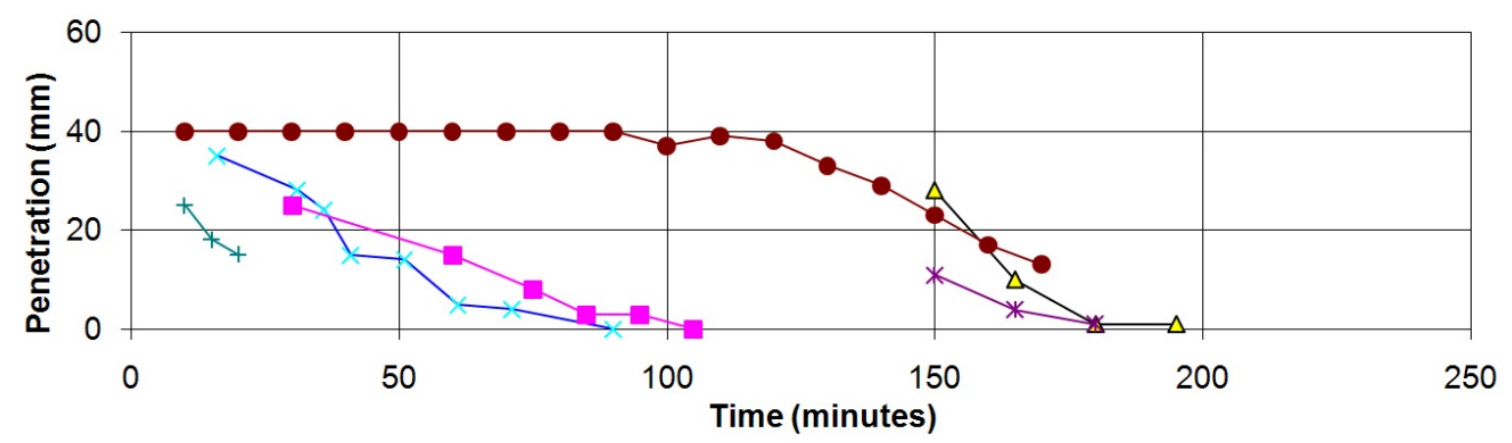

\begin{tabular}{l}
$\rightarrow \leftarrow$ Test: Cement/Water/Accelerator chilled and mixed well \\
$\rightarrow-$ Test: Cement/Water/Accelerator room temp \\
$\rightarrow-$ Test: Cement/Water/Accelerator $40 \mathrm{C}$ \\
$\rightarrow-$ Test: Cement/Water chilled no accelerator \\
\hline
\end{tabular}

Figure 2 VICAT test results showed that the set time reduces with an increase in temperature following the addition of accelerator

The main points from the VICAT needle testing were:

- Temperature has no measurable effect on the VICAT test when performed without accelerator. Set commenced at $2.5-3$ hours after mixing.

- With accelerator at $6 \%$ the trend in the results is that the set time reduces as the temperature increases. For example, at $40^{\circ} \mathrm{C}$ the set commenced within approximately 15 minutes of mixing.

- The shape of the VICAT curve is largely independent of the ambient temperature.

\subsubsection{Maturity testing}

Maturity is the development of shotcrete strength with temperature and time. The maturity is developed using the "Nurse-Saul" function (ASTM C1074-04, 2004) applied to the laboratory and field data obtained.

Samples of the batch were prepared at various cure temperatures and UCS strengths were determined using $50 \mathrm{~mm}$ cube samples. These UCS strengths were determined in a load frame. The various temperatures were maintained by keeping samples in a water bath at three different temperatures: $11,19.5$ and $40^{\circ} \mathrm{C}$.

The results of the laboratory maturity curve determination are shown in Figures 3 and 4 where maturity has been plotted against UCS strength. Figure 3 shows curves with and without additive and Figure 4 the curve with additive. Note that to account for the fact that tests are undertaken on "cube" samples, the UCS strengths have been reduced by $20 \%$ to provide equivalent UCS results more commonly used in rock mechanics testing where the samples are typically 2.5:1.0 (length to diameter). The curves are log scale trend lines plotted to show the line of best fit to the limited data available at present. The main points from the laboratory testing are:

- The $\mathrm{T}_{0}=-3.3^{\circ} \mathrm{C}$.

- If $\mathrm{T}_{0}$ is ignored then the maturity curve and the predictions from the maturity curve could be in error. A plot showing the effect of varying $\mathrm{T}_{0}$ on the Mix 1 design is shown in Figure 5. 


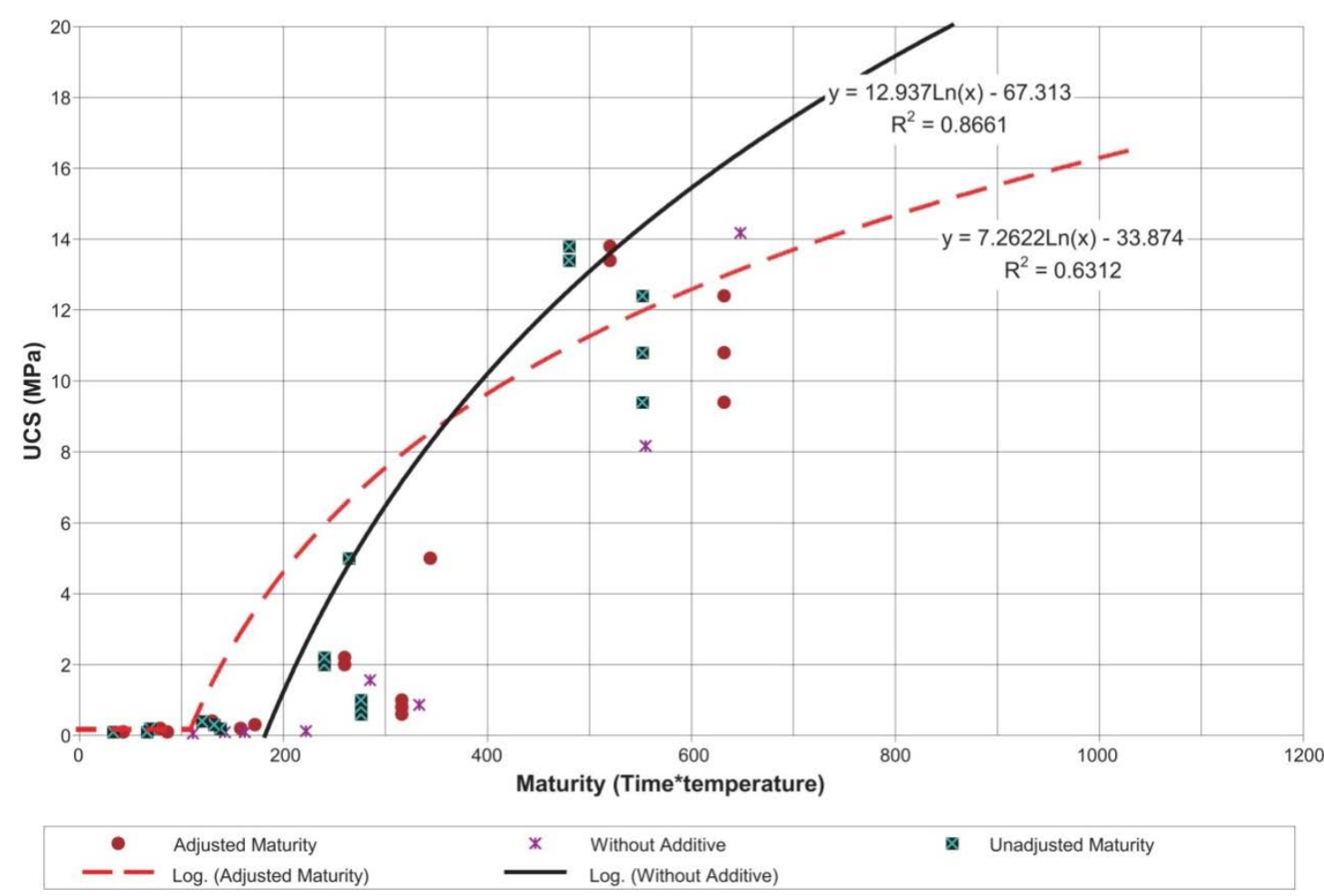

Figure 3 Laboratory maturity curve - dashed line is with additive and the solid line is without additive. Higher early strength gain is achieved using additive

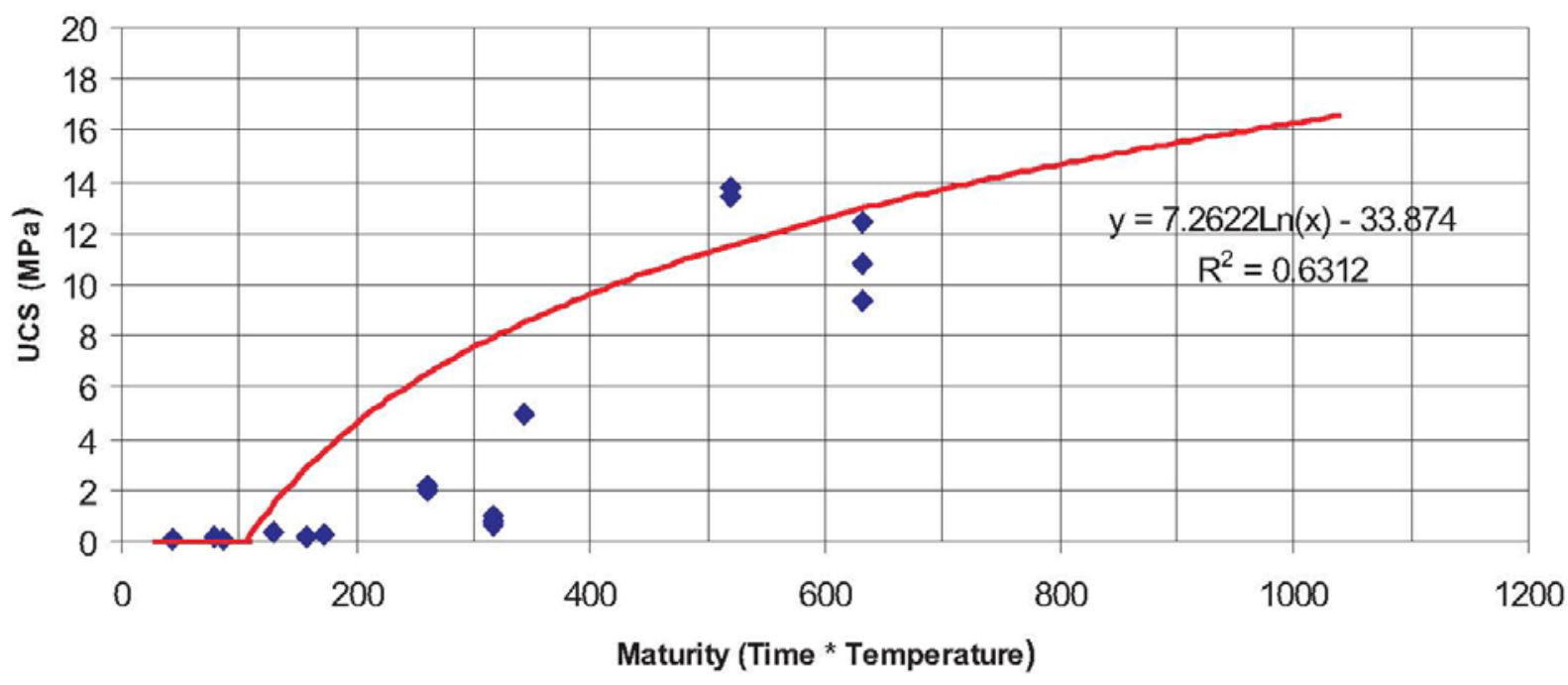

- Adjusted Maturity — Log. (Adjusted Maturity)

Figure 4 Laboratory maturity curve - with additive. This shows that $5 \mathrm{MPa}$ is achieved with a maturity of 200 ; i.e. at $40^{\circ} \mathrm{C}$ in $0.5 \mathrm{hr}$ 


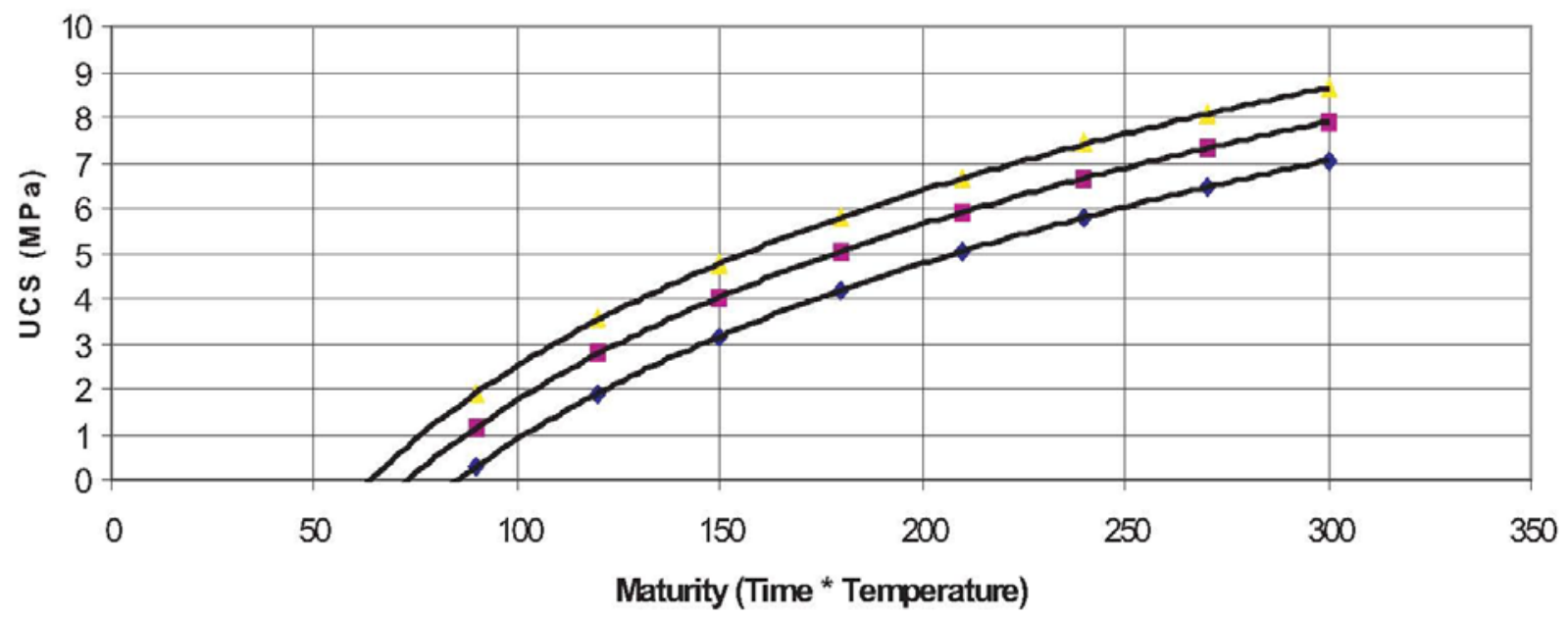

- $T o=0$ degrees $\square T o=-5$ degrees $\triangle T o=-10$ degrees

Figure 5 Laboratory maturity curve - effect of changing $T_{0} ; T_{0}$ is primarily a function of cement grind; earlier strength gain is achieved with a finer grind

\subsubsection{Site trials - beam UCS tests}

\subsubsection{Test results}

The beam UCS testing concept was developed by Rusty Morgan in Canada several years ago (Heere et al., 1999; Heere and Morgan, 2002). The Coffey Mining UCS mini load frame was used to undertake UCS testing of as many samples as were available given the constraints of the mining cycle. The beam mini load frame and gang moulds are shown in Figure 6 and a typical UCS sample is shown in Figure 7.

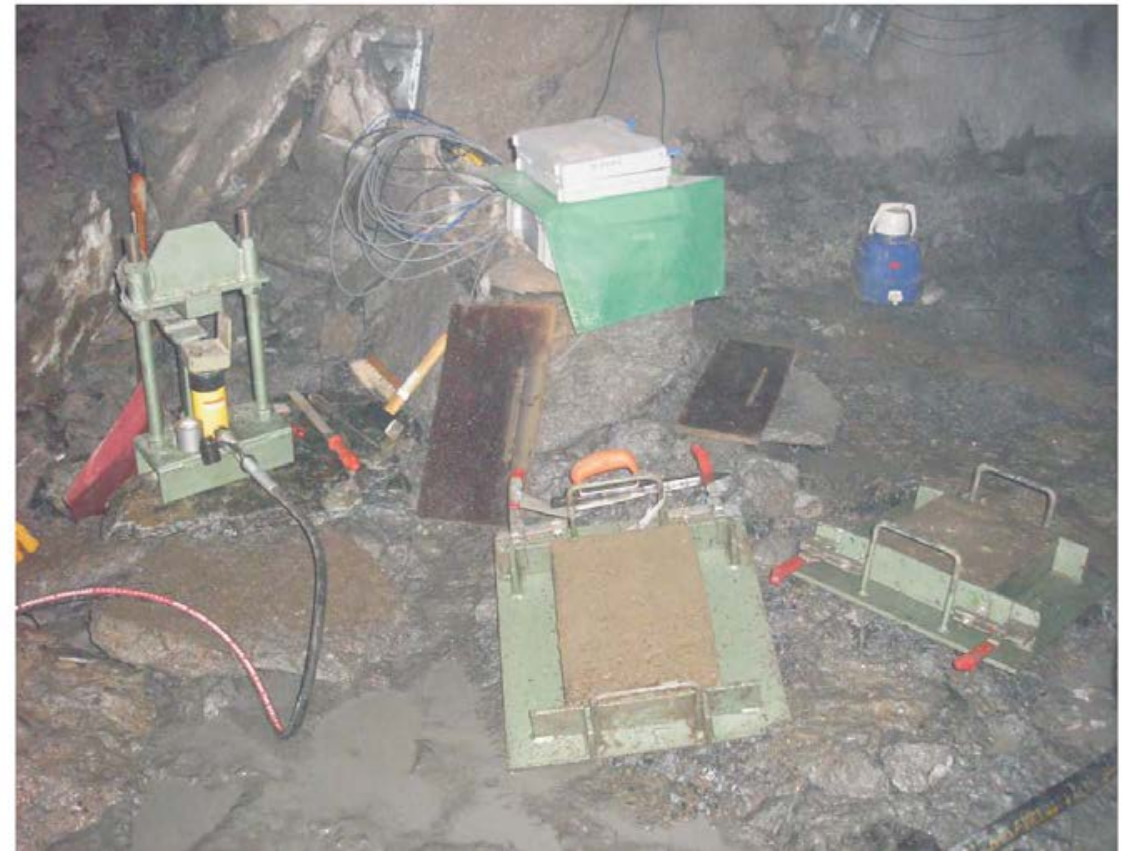

Figure 6 Beam mini load frame and gang moulds set up underground 


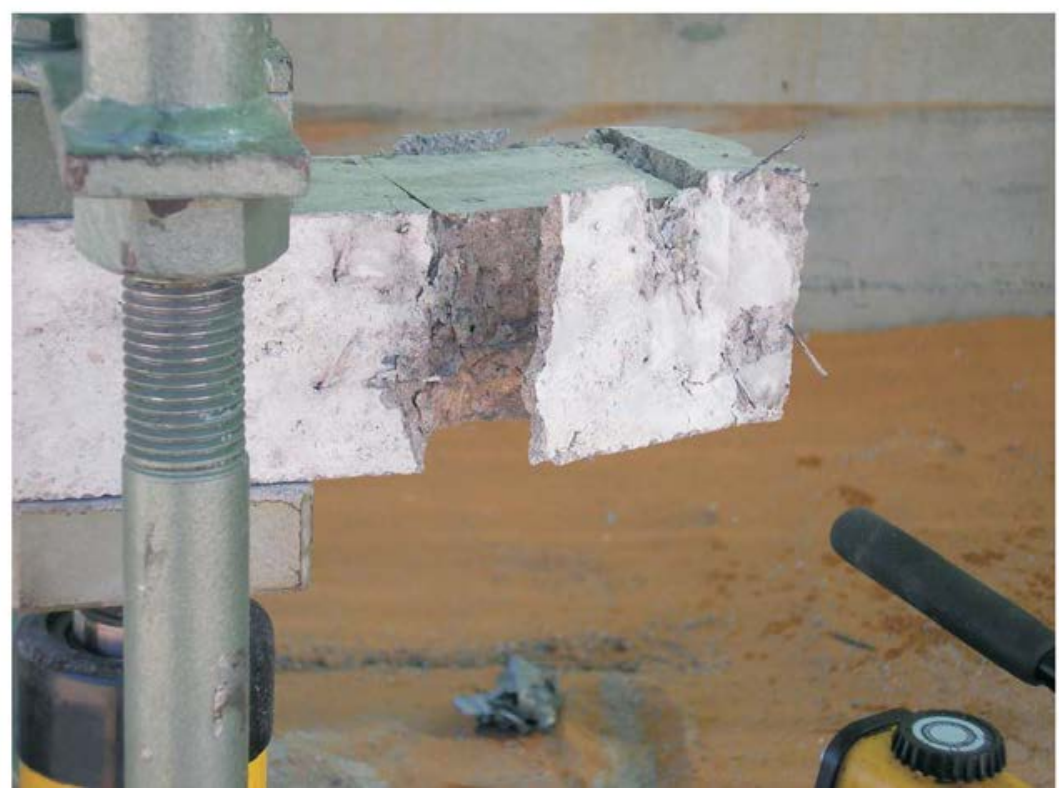

Figure 7 Tested UCS sample - three tests can be undertaken per sample

The results of all $75 \times 75 \mathrm{~mm}$ beam UCS tests for both mix designs have been combined and plotted in Figure 8. The test results over the first eight hours for both mix designs have been combined and plotted in Figure 9. The plots show UCS strength gain with time. The trend lines shown have been plotted on a log scale as this provides the best estimation of the theoretical sinusoidal curve of concrete/shotcrete strength gain with time. A typical data set following the expected theoretical curve is shown in Figure 10 obtained from university tests. As a check on the veracity of Mix 2, a log scale plot and log scale trend line was produced. This plotted as a straight line through the data points indicating that a log scale trend line is appropriate (Figure 11).

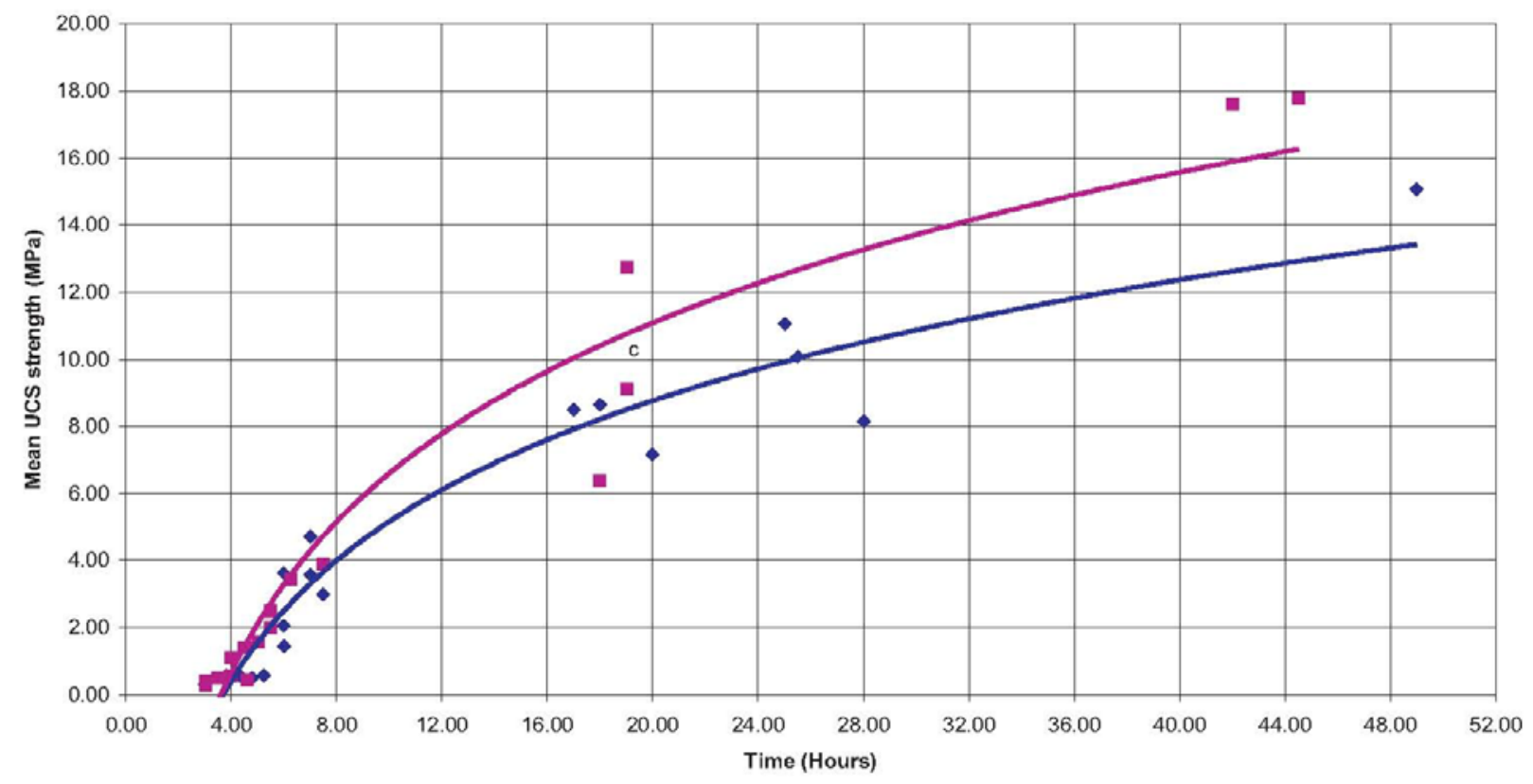

- Time vs Corrected Strength plot a Time July 06 - Log. (Time vs Corrected Strength plot) — Log. (Time July 06)

Figure 8 UCS strength gain with time — combining July and August 2006 data 


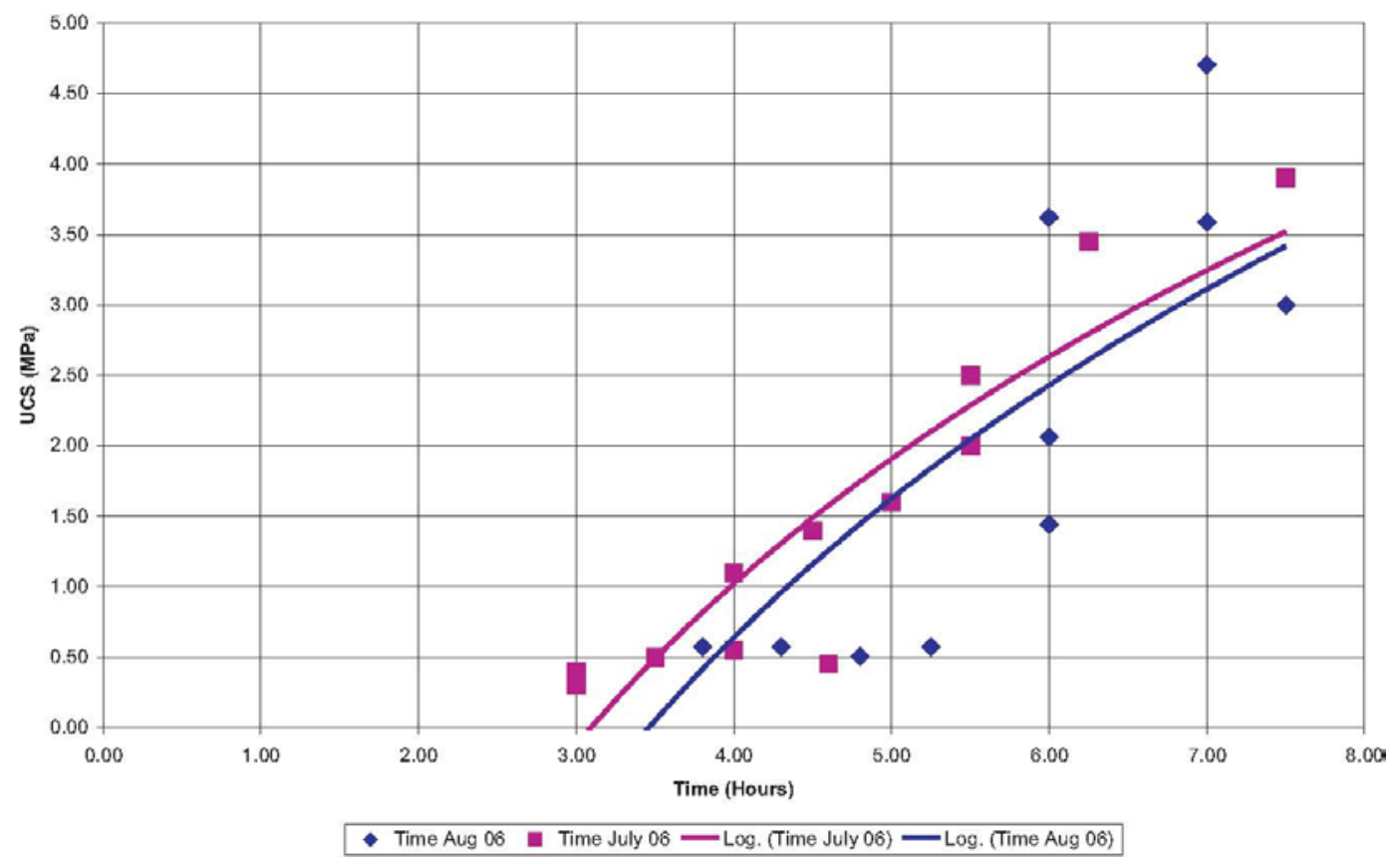

Figure 9 UCS strength gain with time - first eight hours data

\section{Time vs UCS strength}

After University of WA
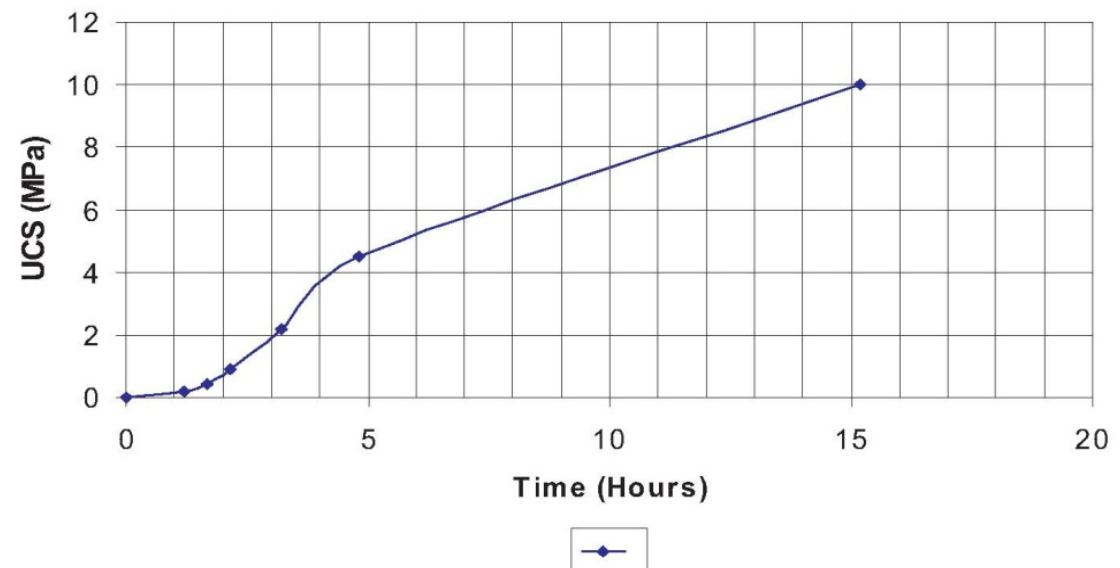

Figure 10 Typical UCS strength gain with time (de Haas, 2005; Georgiades, 2005) 


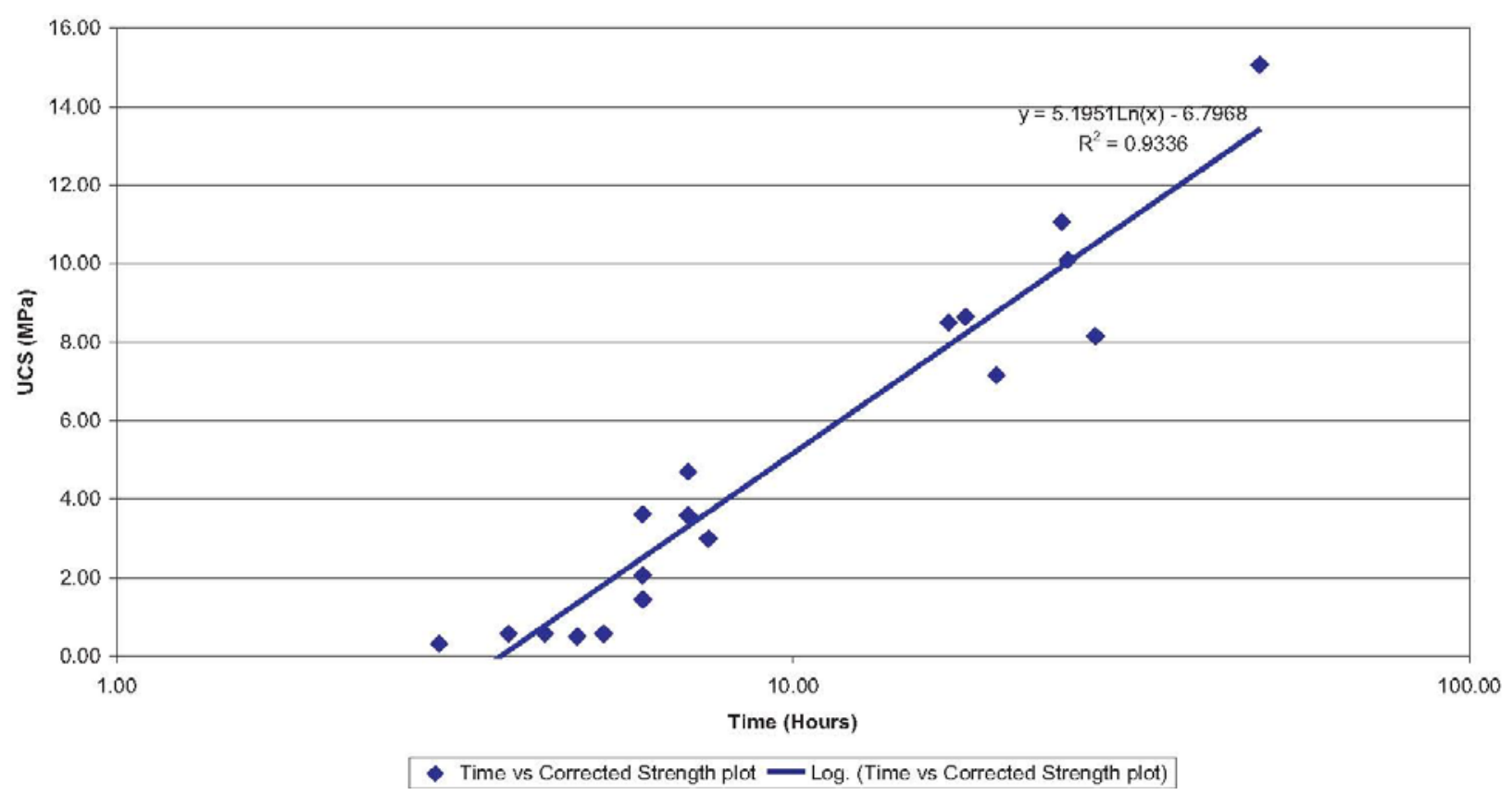

Figure 11 UCS Strength gain with time -75 x 75mm data Mix 2

\subsection{Discussion}

The main points learnt from the UCS testing were:

- Testing of beams can be undertaken as low as $0.5 \mathrm{MPa}$ strength. At this strength the material fails by bulging, which is typical of ductile materials and can be difficult to pick.

- Testing is quick and simple within the range of 1.5 MPa to maximum load of the load frame of $25 \mathrm{MPa}$.

- Testing to date indicates strength gains of up to $22 \mathrm{MPa}$ in less than 48 hours since application at ambient temperature.

Differing results were obtained for each of the two mix designs.

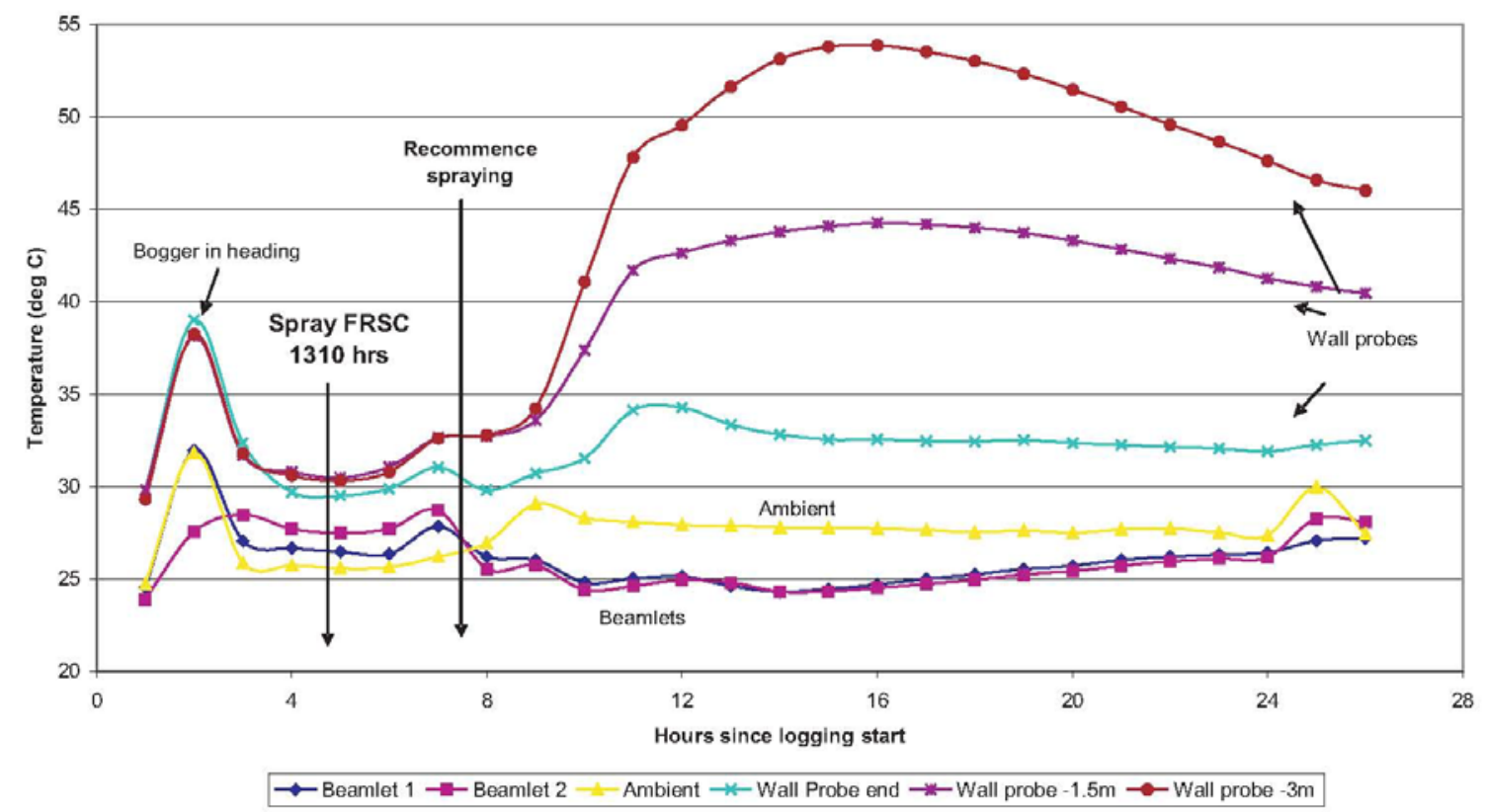

Figure 12 Temperature monitoring - using the temperature probes in 361 Viper Bay 


\section{Site trials - maturity concept}

\subsection{Test results}

Temperature data for verification of the laboratory maturity curves was obtained by embedding thermocouple wires within the sprayed shotcrete liner (Figures 12 and 13). These were monitored on a continual basis by a data logger at the face. Additional temperature data was obtained during the second site visit by employing a laser temperature monitoring unit (Figure 14). This unit, when used at four metres from a wall, averaged the data over an approximate $600 \mathrm{~mm}$ diameter circle. Up to five readings for each sprayed panel were taken at regular intervals. This unit was also used to provide temperature data for the UCS beam samples.

A total of three separate heading applications were monitored during the site visits. As the shotcrete cured, UCS cube strengths were determined using the beam mini load frame at regular time intervals or as determined by the mining cycle (note that the cube results should be reduced by 0.8 to provide equivalent UCS results more commonly used in rock mechanics testing where the samples are typically 2.5:1.0 length to diameter).

The temperature monitoring results for the three headings are shown in Figures 12-14. These plots include relevant details on the main activities during the monitoring period.

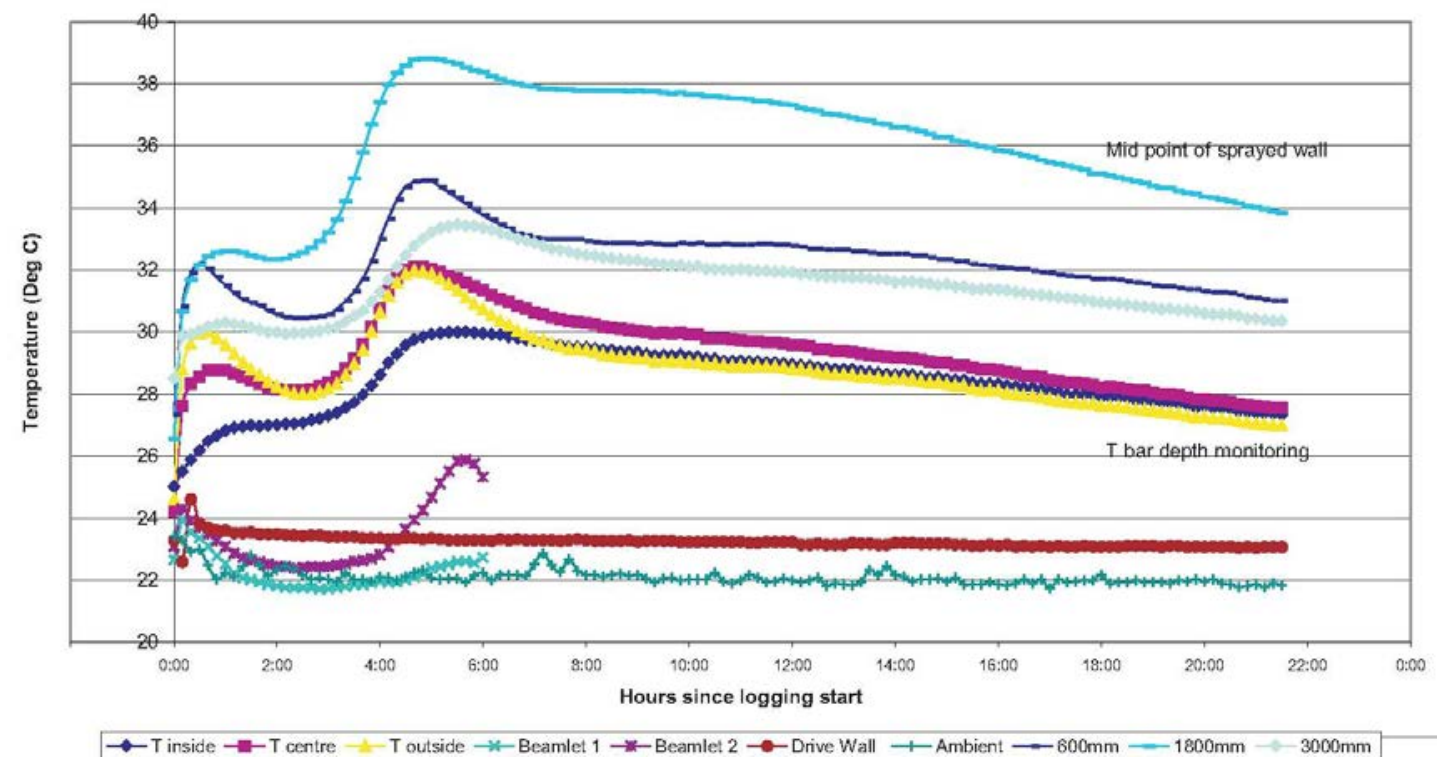

Figure 13 Temperature change recorded using the thermocouples 


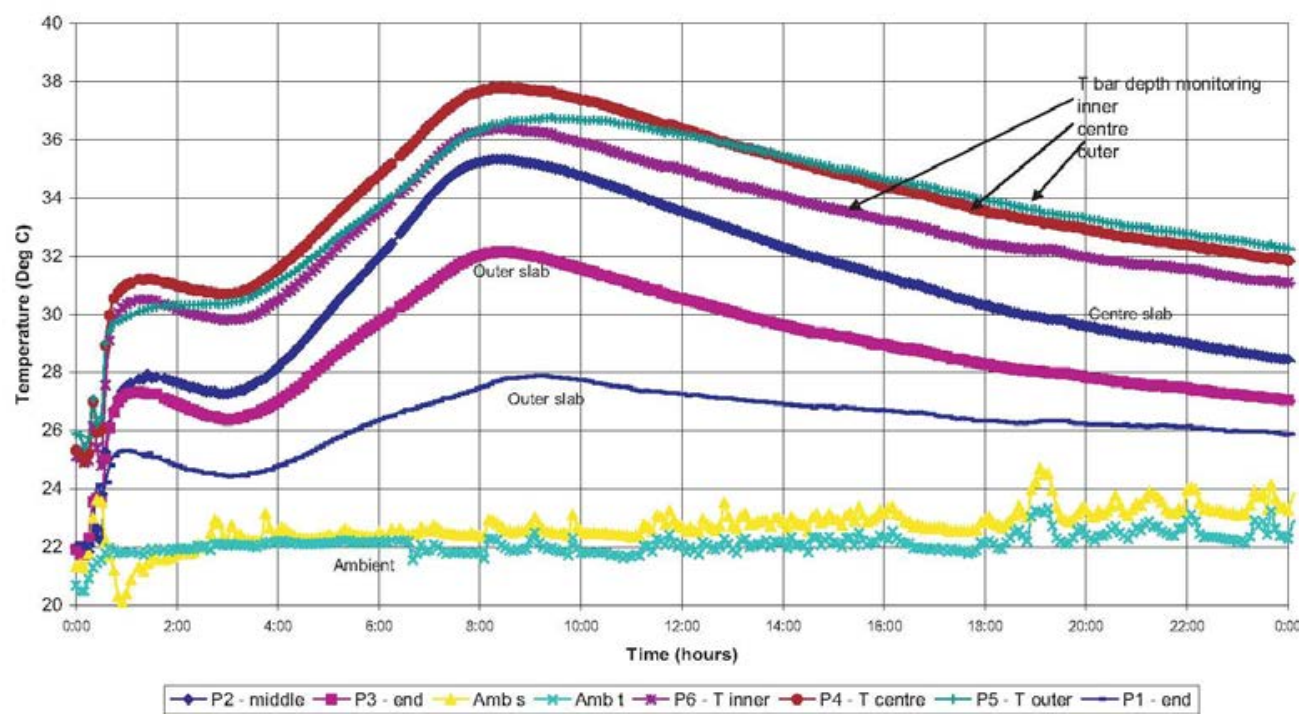

Figure 14 Temperature variation across the back with time at different locations using thermocouples and correlation with the laser gun (Figure 18)

The maturity of both Mix 1 and Mix 2 are presented in Figures 15 and 16. Figure 15 shows maturity with respect to UCS strength and Figure 16 shows maturity with respect to shear strength. The actual strength gain in the field was measured usuing the Mecmesin penetrometers. The results are shown in Figure 17. The maturity results at two hours $\left(2 \times 30^{\circ} \mathrm{C}=60\right)$ would give a strength of approximagely $0.5 \mathrm{MPa}$ as shown in Figure 16.

Production of a maturity curve allows strength estimation to be undertaken from elapsed time and temperature data. Temperature monitoring using the laser gun (Figure 18) recorded against time at 361 Viper Bay allowed an initial verification of this concept with in situ UCS strength testing checked against the estimated maturity value.

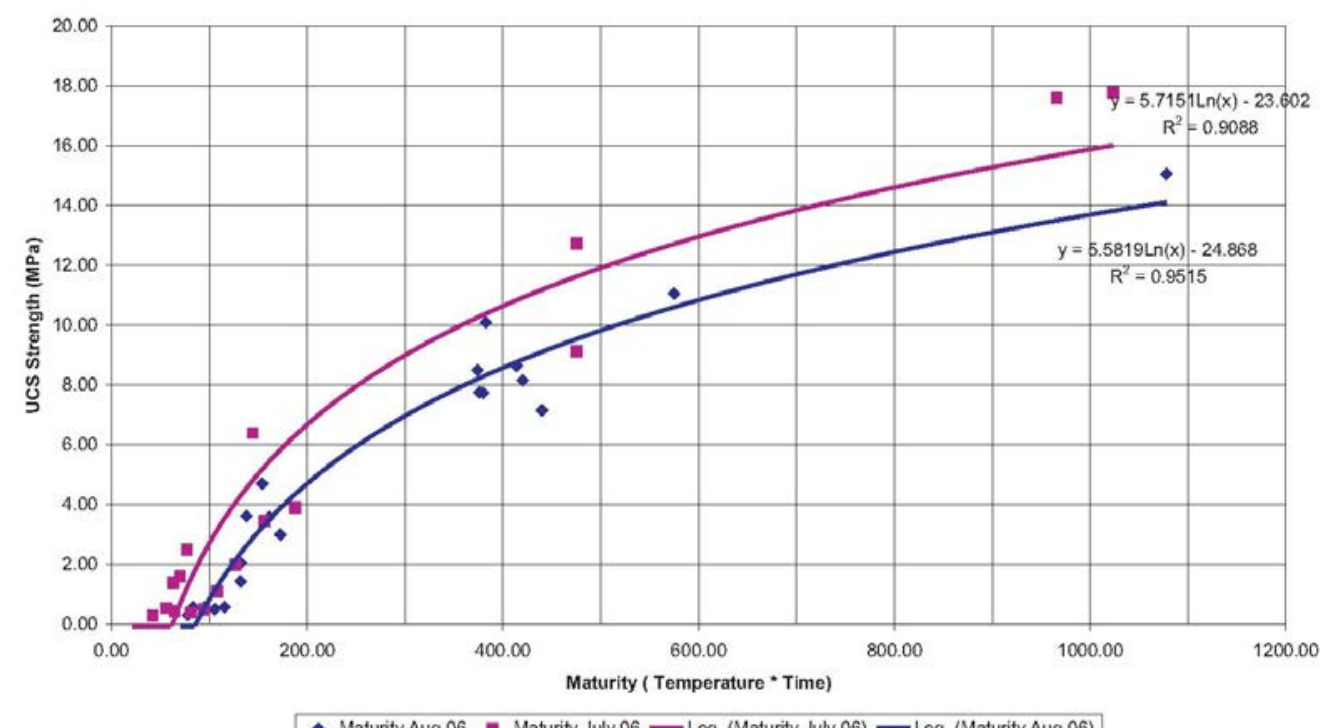

Figure 15 Mix 1 - maturity curve with $T_{0}$ correction 
Maturity and Corrected Maturity vs UCS Strength - August 2006

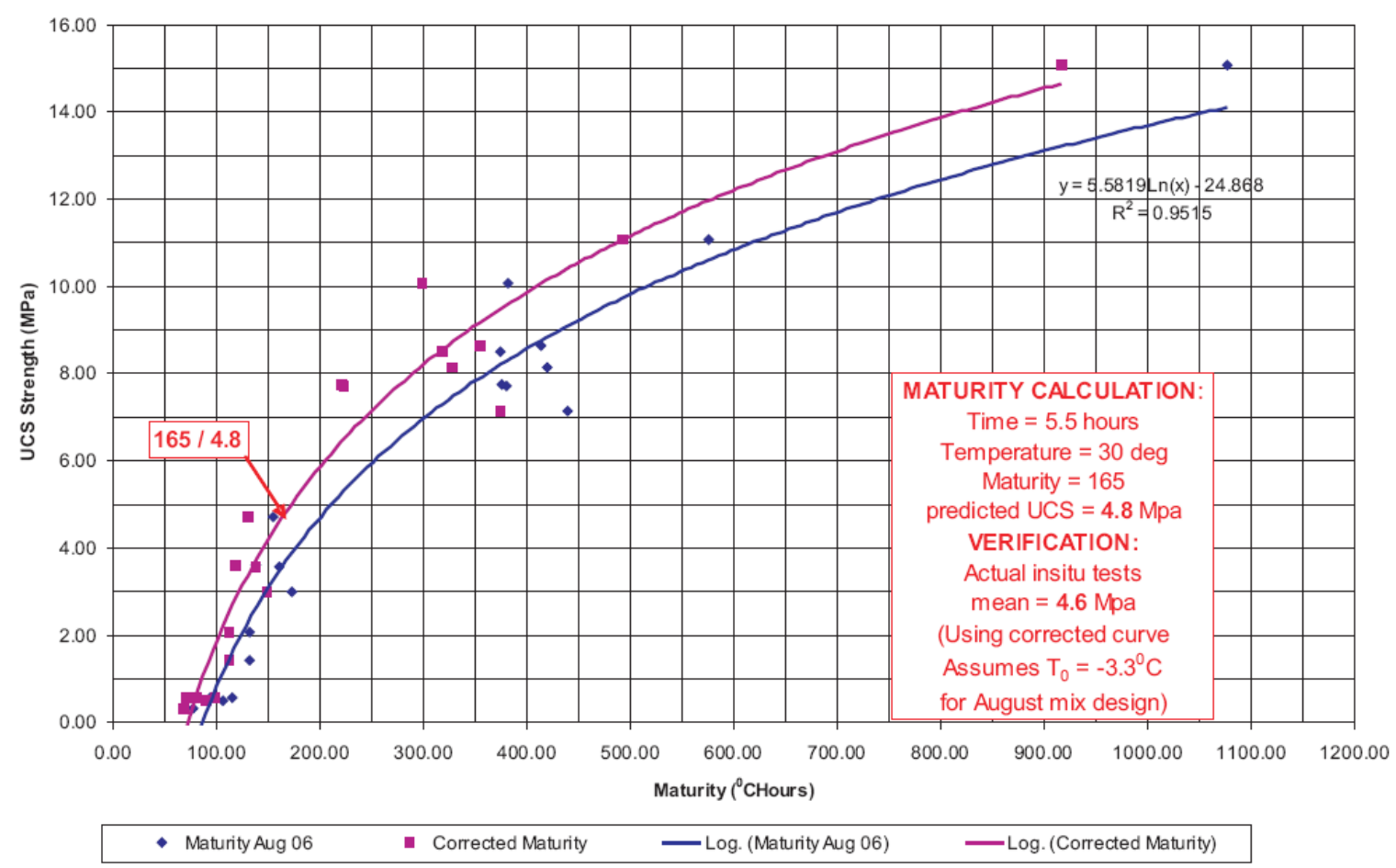

Figure 16 Maturity verification calculations for Mix 2

Penetrometer Strength Monitoring - 3mm Probe

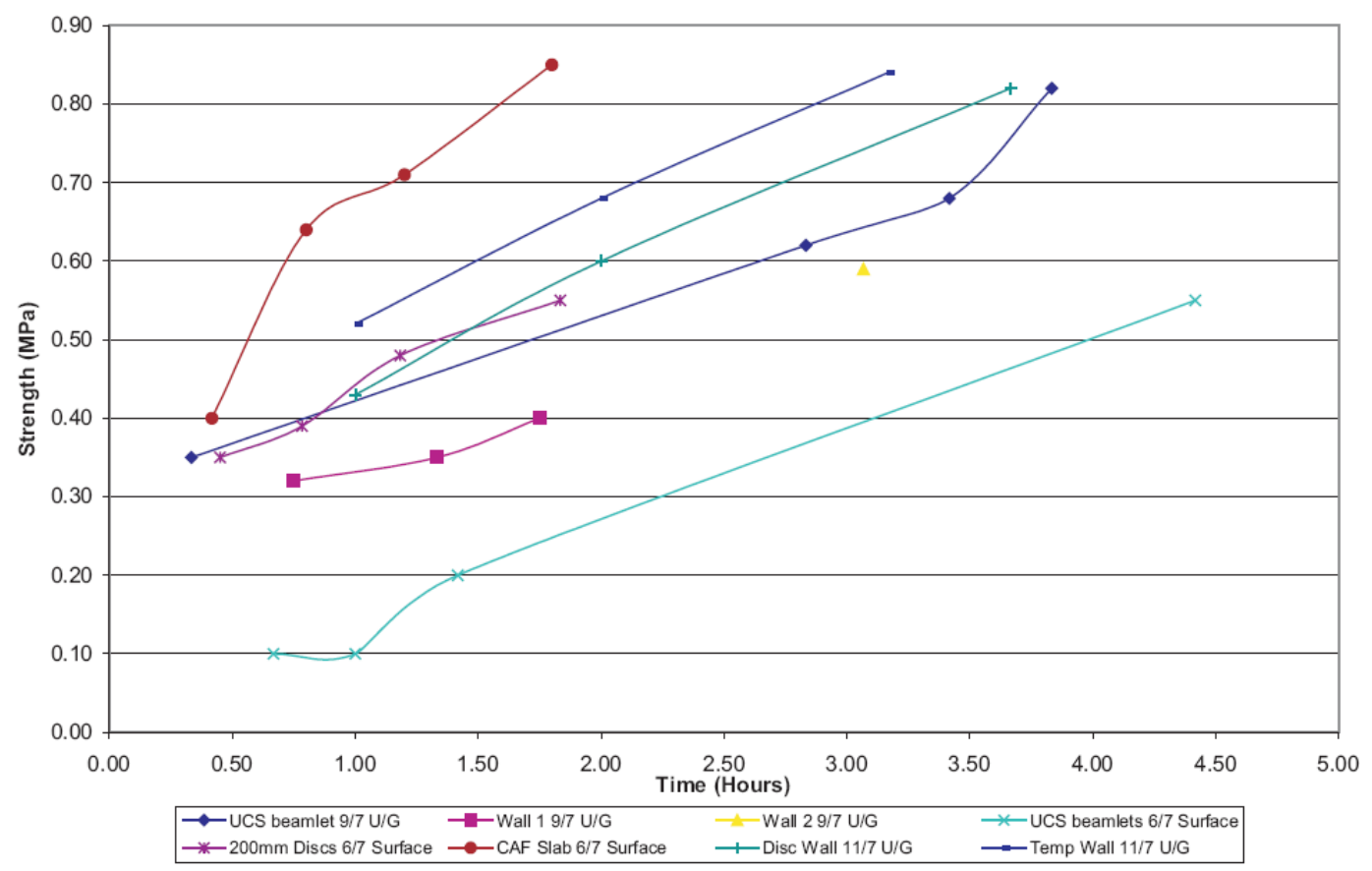

Figure 17 Mecmesin penetrometer UCS strength estimation 


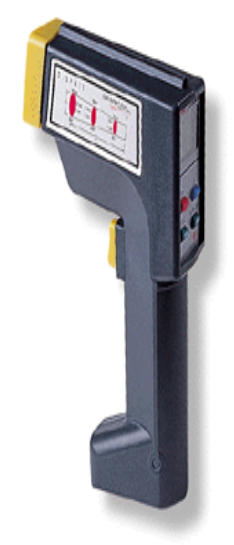

Figure 18 Temperature monitoring equipment - Model 8866, non-contact IR infra red thermometer

\subsection{Discussion}

The main points learnt from the maturity laboratory testing and site work were:

- Monitoring indicates a higher temperature is attained at the centre section of the sprayed mass, rather than at the edges. This will have implications with respect to the influence of thickness of a panel (i.e. a thicker panel may achieve a higher temperature and hence a higher early strength compared to a thin panel) and the inferred strength profile in the early age behaviour (i.e. weaker towards the edge of the panel compared to the centre).

- Monitoring indicates temperatures up to $20^{\circ} \mathrm{C}$ above ambient within the sprayed mass during the cure stage and these elevated temperatures remain for up to 24 hours or more.

- Maturity is strength gained with time and temperature. The planned approach of testing strength gain related to temperature rise of the applied shotcrete at the face, using gang moulds sprayed and cured at the test site, this was not achieved during the first site visit. The temperature in the moulds remained at ambient. This is attributed to the low mass of sprayed shotcrete in the mould which did not reach the elevated temperatures attained within the larger mass sprayed on the wall, and the thermal properties of the steel mould which acts as a heat sink. It is probable that a similar effect is occurring with the steel agitator, effectively lowering the delivered shotcrete temperature in winter and possibly elevating the temperature in summer. Based on our recent laboratory results the lower initial temperature delays the onset of the set. This may be one reason that more accelerator is often used by operators to overcome the situation.

- A complete maturity curve was produced for the Mix 1 design and the site component maturity curve was determined for the Mix 2 design (Figures 15 and 16 respectively). From these plots it can be seen that varying the components within a particular mix design has a direct result on the performance of that particular mix. A new set of maturity curves must be developed for any significant change in mix design. This is borne out by the test results obtained during this project.

- Temperature monitoring recorded against time since application of shotcrete has allowed determination of estimated UCS strength using the maturity curve for Mix 2.

\subsection{Site trials - penetrometer UCS estimation}

\subsubsection{Test results}

A Mecmesin electronic force gauge was trialled which was fitted with a $15 \mathrm{~mm}$ long, $3 \mathrm{~mm}$ diameter tip to determine an estimated UCS strength of shotcrete application areas as they cured. The tip dimensions correspond to that fitted to the Meyco penetration needle commonly used for early strength estimation. Practical use of the Mecmesin gauge was simple, with no damage to the tip reported. This is most likely due to the lower amount of force and leverage available from a small hand held device. However sufficient force could be applied to reach the maximum estimated strength of about $0.8-0.9 \mathrm{MPa}$ available from this type of 
monitoring of shotcrete cure. A combined plot of all relevant penetrometer data has been included in Figure 17. Use of the Mecmesin gauge is shown Figure 19.

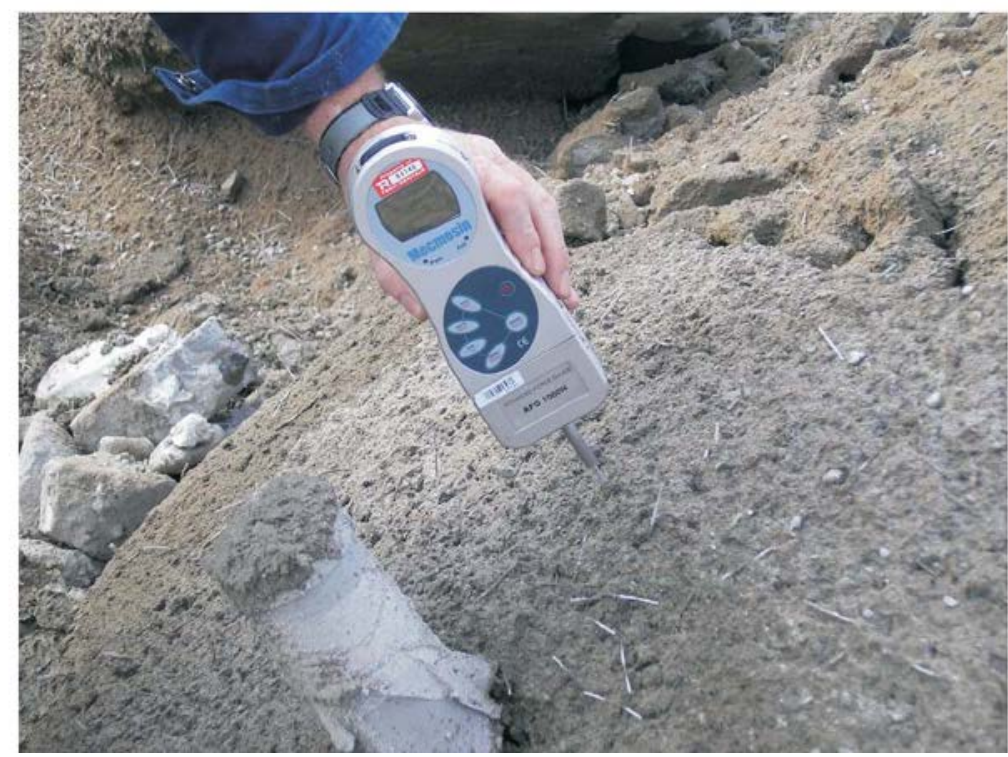

Figure 19 Mecmesin force gauge using a $3 \mathrm{~mm}$ diameter needle gives consistent results

\subsubsection{Discussion}

The main points developed from use of an electronic force gauge were:

- The electronic force gauge was simple, quick and easy to use.

- Refusal of the $3 \mathrm{~mm}$ diameter tip occurs at about 0.8 - 0.9 MPa strength. Correlation was obtained between the low strength UCS beam tests undertaken and the penetrometer testing undertaken on curing beam samples. It is anticipated that the results may need to be normalised to the time corresponding to the onset of set. This is based on preliminary laboratory results which show that this time is significantly affected by the initial temperature of the mix at the time of spraying.

\subsection{Site trials - beam flexural strength tests}

\subsubsection{Test results}

Part of the initial testing program called for trialling of beam testing to see if meaningful flexural strengths and hence toughness, could be taken on-site, particularly in the first hours or days following shotcrete application. Existing standards use beams and round determinate plate tests to determine flexural strength (AS 1012-11, 1985; ASTM C1550, 2003). Typically these results are reported at seven days cure and more commonly at 28 day cure. Trial samples were cast and tested at about two and 48 hours cure.

\subsubsection{Discussion}

The main points from the initial trials on beam flexural strength tests were:

- Preliminary test results indicate that the flexural strength of the shotcrete is about $0.6-0.8 \mathrm{MPa}$ at less than 48 hours cure.

- The preliminary test rig was deemed unsuitable for accurate flexural strength testing. Flexural testing requires a controlled displacement jack to obtain accurate results. 


\section{$5 \quad$ Conclusions and recommendations}

The focus of this has been on developing and refining a simple suite of laboratory and site tests required to obtain these parameters for any particular mix design that may be used. This was accomplished using laboratory and site testing to obtain data for the maturity concept.

\subsection{Laboratory testing}

The VICAT testing results are a good indicator of initial set times. The test process is simple and quick to undertake. The results from the VICAT testing suggest that reduced temperature at mix time delays the onset of the set. Once the set commences however, the time taken to complete the set is so far the same given the ambient temperature. This is verified by the site practice of adding chilled water to the mix at the time of batching to delay the onset of the set during the hot summer months. The VICAT test does provide an indication of the accelerator effectiveness. Further tests could be undertaken to evaluate the influence of percentage of accelerator on set times.

\section{$5.2 \quad$ Site testing}

\subsubsection{Temperature monitoring}

The temperature monitoring results, in addition to providing data for the maturity of the mix, have given an insight into the temperature gradients that develop within the applied shotcrete layer in a heading. The temperature in the centre of the panel is hotter than the outside. The consequence is that the centre of the panel is gaining strength faster than the outside - this may also have implications for wall support (outside edge of panel) and where panels join between cuts. The laser temperature gun was more flexible to use than the thermocouple probes as it was portable and could be used in any heading.

\subsubsection{UCS strength on $75 \times 75 \mathrm{~mm}$ samples}

The beam test rig is quick and simple to use and provides reliable UCS data on $75 \mathrm{x} 75 \mathrm{~mm}$ samples from about 1.5 MPa up to capacity of the mini load frame at $25 \mathrm{MPa}$. The actual failure point is difficult to pick below this value as the shotcrete is still "plastic" and tends to bulge rather than crack, however with appropriate pressure gauges and technique, fairly accurate strength values can be obtained.

\subsubsection{Penetrometer}

The electronic force gauge worked well and provided valuable data up to about $0.9 \mathrm{MPa}$ strength. Future work should focus on developing a simple screwdriver based $3 \mathrm{~mm}$ probe for strength estimation along with investigating the recalibration of the pocket penetrometers currently in use as a guide to early set times.

\subsubsection{Beam flexural tests}

The initial testing was promising. Modifications to the test rig are planned, including a screw feed jack to provide a constant displacement load to the test sample.

\subsection{Maturity curve determination summary}

The programme of laboratory and site work has been successful in detailing the maturity curve Mix 1 . The Mix 2 design follows closely but lacks laboratory determination of the low temperature parameters. The main conclusions and recommendations from this are:

- For Mix $1, \mathrm{~T}_{0}$ was between $-3.3^{\circ} \mathrm{C}$ (lab) and $-5.5^{\circ} \mathrm{C}$ (field). The impact of a lower $\mathrm{T}_{0}$ is to achieve earlier strength gain. This may be achieved by sourcing a cement with a finer grind and would be most important where the ambient temperature is low.

- There is a minor difference in the maturity curve start point ( $\mathrm{X}$ axis intercept) between the Mix 1 laboratory and site testing. This is possibly due to the differing cube UCS sample sizes of $50 \mathrm{~mm}$ for the lab and $75 \mathrm{~mm}$ on-site and also the differing curing conditions between the lab and site. 
- Varying the components within a particular mix design has a direct result on the performance of that particular mix. Reference documents describing the maturity concept report that a new set of maturity curves must be developed for any significant change in mix design. This is borne out by the test results obtained during this project.

- Obtaining maturity data on-site proved to be difficult and time consuming, mainly due to the constraints of the mining cycle in a small and busy mine with most accessible headings being developed as often as possible, typically twice per 24 hour period.

- Initial trials indicated that strength estimations are possible using the maturity curve developed for a particular mix by recording temperatures at regular intervals using the laser temperature gun and noting the time since application/initial set.

- For early re-entry, the site test work has indicated that for the mix designs and locations tested, shotcrete will most likely be less than $1 \mathrm{MPa}$ strength for up to four hours post application. The $1 \mathrm{MPa}$ strength criterion was based on achieving a shear strength of $0.3 \mathrm{MPa}$ assuming a $50 \mathrm{~mm}$ thickness of shotcrete. Analyses using Unwedge have been used to support this criterion. This assumed boltless shotcrete where the back span was typically more than five metres. The practice of bolting, say $1.5 \times 1.5 \mathrm{~m}$ spacing, means that the shotcrete is only supporting scats between these bolts. Hence the practice of bolting before the compressive strength has achieved $1 \mathrm{MPa}$ assumes that the green material has sufficient strength to support these scats.

- There are many aspects of the application of shotcrete in mining which differ from its application in civil engineering. As a consequence there is a pressing need for the development of a Code of Practice for the application of shotcrete in mining. This stems initially from the work described here looking at the influence of temperature in particular on the early strength characteristics of shotcrete. However, there are many influences which have not been taken into account in this work such as the effect of cement grind on the rate of cure. The authors have been involved in projects where the rock temperature has ranged from $8-54^{\circ} \mathrm{C}$ and where the cement supplied has been obtained from the cheapest source. This is understandable when it is unclear that grind can have a major influence on the cure time - this is rarely specified and once the purchasing department is engaged their role is to minimise costs. At the mine where the rock temperature was $8^{\circ} \mathrm{C}$ the shotcrete rarely set within four hours.

- The use of the beam tests and the use of the Meyco penetrometer are currently the most reliable methods of obtaining early strength results. There is still a significant issue relating to statistical sampling with a fast repeatable which is independent of the operator. The use of the shear wave reflection technique (Akkaya et al., 2003; Sun et al., 2005) or the shear wave velocity (Harris, 2008) show good potential for non-destructive testing of the shotcrete prepared underground and may be more reliable as a statistical method of obtaining strength data with time and temperature.

\section{Conclusions}

It is clear from the foregoing work that the influence of temperature is a significant issue within Australian mines. Taking maturity into account is one step in achieving a much better correlation in the strength relationship between samples prepared in the field and removed to on-site laboratories or remote laboratories and the in situ shotcrete. It is important to remember that the mining environment is significantly more variable than the civil engineering environment from which all of the test procedures have been adopted. The relevance of these tests procedures in the mining environment should be rigorously examined.

It is acknowledged that maturity may only be part of the solution. There are a number of outstanding issues which still have to be addressed:

- The development of a Code of Practice for the use of shotcrete applicable to the mining environment.

- The development of representative/reliable testing applicable in the mining environment (Harris, 2008) that can take into account statistical variability. 
- The effect of blasting on young shotcrete (Ansell, 2002).

- The influence of squeezing ground (e.g. creep) on the early strength of shotcrete.

- The influence of adhesion and the surface preparation.

- The influence of sulphate attack on shotcrete adhesion.

\section{Acknowledgements}

The work presented here has been undertaken over a number of years. The authors acknowledge the support of their colleagues at Coffey Mining; Darren Howard from Barminco; Dean Will from Mincor; Doug Minchin from ROCK Australia; Peter Denham from ReadyMix; Frank Papworth; Ray Desmond from Radmix; Rod McKenzie from BASF; Ken Kavanagh at The University of Western Australia and the honours students Brian Harris; Marcus de Haas and James Georgiades from The University of Western Australia.

\section{References}

Akkaya, Y., Voigt, T., Subramaniam, K.V. and Shah, S.P. (2003) Non-destructive measurement of concrete strength gain by an ultrasonic wave reflection method. RILEM.

Ansari, F., Luke, A. and Maher, A. (1998) Development of FastTrack Concrete-2. Final Report. Federal Highway Administration, US Department of Transportation Washington D.C., Report No: 2001-014.

Ansari, F., Luke, A., Dong, Y. and Maher, A. (1999) Development of Maturity Protocol for Construction of NJDOT Concrete Structures. Final Report. Federal Highway Administration, US Department of Transportation Washington D.C., Report No: 2001-017.

Ansell, A. (2002) A Literature Review on the Vibration Resistance of Young and Early Age Concrete. Royal Institute of Technology, Structural Engineering Stockholm. Report 68.

American Society of Testing Materials, Standard (ASTM) C1074-04 (2004) Standard Practice for Estimating Concrete Strength by the Maturity Method.

American Society of Testing Materials, Standard (ASTM) C1550 (2003) Standard test method for Round Determinate Panel determination of the Flexural strength of Concrete Specimens.

Australian Standard (AS) 1012-11 (1985) Method for the determination of the Flexural strength of Concrete Specimens.

Australian Standard (AS) 3600 (2001) Concrete structures.

Arrhenius, S. (1889) On the reaction rate of the inversion of non-refined sugar upon souring, Z. Phys. Chem. 4, pp. 226-248.

Bernard, E.S. (2008) Early-age load resistance of fibre reinforced shotcrete linings. Tunnelling and Underground Space Technology, 23, pp. 451-460.

Chengyu, G. (1989) Maturity of Concrete: Method of Predicting Early-Stage Strength. ACI Materials Journal, 86:4, July-August, pp. 341-353.

Clements, M.J.K. (2004) Comparison of Methods for the Early Age Strength Testing of Shotcrete. Grenz Pty Ltd., Australia.

de Haas, M. (2005) Early Time Behaviour of Fibre Reinforced Concrete. Final Year Honours Thesis, University of Western Australia, Perth, Australia.

Dufour, J-F., O’Donnell, J.D. and Ballou, M. (2003) Determination of Early Age Ductility of SFRS Lining System at Inco’s Stobie Mine. Shotcrete Magazine, Spring 2003, pp. 10-15.

Georgiadis, J. (2005) Early Time Behaviour of Fibre Reinforced Concrete: Creep and Relaxation. Final Year Honours Thesis, University of Western Australia, Perth, Australia.

Goodrum, P.M., Dai, J., Wood, C.R. and King, M. (2004) The Use of the Concrete Maturity Method in the Construction of Industrial Facilities: A Case Study. FIATECH Report.

Harris, B. (2008) Prediction of compressive strength from shear wave velocity. Final Year Honours Thesis, University of Western Australia, Perth, Australia.

Heere, R., McAskill, N. and Morgan, D.R. (1999) Determination of Early-Age Compressive Strength of Shotcrete, Third International Symposium on Sprayed Concrete, Gol, Norway, Norwegian Concrete Association, 525 p.

Heere, R. and Morgan D.R. (2002) “Technical Tip” - Determination of Early-Age Compressive Strength of Shotcrete. Shotcrete Magazine, Spring 2002, pp. 28-31.

Kim, D-G., Lee, G-P. and Bae, G-J. (2006) Compressive and Adhesive Strengths of Shotcrete Deteriorated by Hazardous Components in the Ground Water. Tunnelling and Underground Space Technology, 21, p. 323.

Kuchta, M., Hustrulid, W. and Lorig, L. (2003) The Importance of Rock Surface Preparation in Shotcrete in Operations. Third International Seminar on Surface Support Liners, Quebec City, Canada, pp. 283-290. 
Mancio, M., Harvey, J.T., Ali, A. and Zhang, J. (2004) Evaluation of the Maturity Method for Factual Strength Estimation in Concrete Pavement. Draft Report Prepared for: California Department of Transportation. Institute of Transport Studies, University of California Berkeley and University of California Davis.

Nurse, R. (1949) Steam curing of concrete. Magazine of Concrete Research, 1:2, pp. 79-88.

Öztürk, T., Krogge, O. and Grübl, P. (2004) The Influence of Temperature on the Hydration Process of Concrete Evaluated through Ultrasonic Technique. Proceedings of RILEM - International Symposium on Advances in Concrete through Science and Engineering, Evanston, Illinois, United States of America, CD-ROM.

Saul, A. (1951) Principles underlying the steam curing of concrete at atmospheric pressure. Magazine of Concrete Research, 2:6, pp. 127-140.

Sun, Z., Voigt, T. and Shah, S.P. (2005) Temperature Effect on Strength Evaluation of Cement-Based Materials with Ultrasonic Wave Reflection Technique. ACI Materials Journal, 102:4, July-August, pp. 272-278.

Zhang, J., Cusson, D., Monteiro, P. and Harvey, J. (2008) New Perspectives on Maturity Method and Approach for High-Performance Concrete Applications, Cement and Concrete Research, 38, pp. 1438-1446. 